CP, 2020, Vol.9 - No19, pp. 9/24 ISSN 2014-6752. Girona (Catalunya). Universitat de Girona. OLMEDO SALAR, S.; LÓPEZ VILLAFRANCA, P.: Análisis de un modelo de ciudad turística según las fuentes del relato: prensa versus plataformas ciudadanas. ¿Especulación o desarrollo? Recibido: $30 / 09 / 2020$ - Aceptado: $19 / 11 / 2020$

\title{
Análisis de un modelo de ciudad turística según las fuentes del relato: prensa versus plataformas ciudadanas. ¿Especulación o desarrollo?
}

\section{Analysis of a tourist city model according to according to the sources of the story: press versus citizen platforms. Speculation or development (1)}

\author{
Autoras: \\ Silvia Olmedo Salar \\ http://orcid.org/0000-0001-7193-3009 \\ Universidad de Málaga Spain \\ Paloma López Villafranca \\ PhD Contratada Doctora \\ http://orcid.org/0000-0003-4193-1365 \\ Universidad de Málaga Spain
}

(1) Este estudio forma parte de una investigación del proyecto de investigación financiado por la Universidad de Málaga (PPIT.UMA.B1.2017/25).

\section{Resumen:}

Este estudio analiza las fuentes de las que parten las informaciones en dos proyectos que cuestionan el modelo turístico de Málaga (España): Bosque Urbano para Málaga (2016) y la Torre del Puerto (2016). El primero de ellos hace referencia a una construcción descontrolada donde demandan un bosque urbano de 177.000 metros cuadrados y, el segundo, a la edificación de un hotel de 150 metros en el puerto de la ciudad. Los objetivos de la investigación son: analizar y comparar las fuentes en tres diarios de referencia en la provincia y en las redes sociales de dos plataformas ciudadanas. La metodología utilizada es mixta, cualitativa y cuantitativa, análisis de contenido de las noticias y mensajes en redes sociales. Como conclusión principal se aprecia una confrontación de relatos de los medios y los ciudadanos, que reclaman un modelo de ciudad sostenible frente a la prensa, que muestra una defensa de los proyectos urbanísticos analizados esgrimidos por posturas interesadas de fuentes institucionales y privadas.

Palabras clave: Fuentes, prensa, redes sociales, plataformas ciudadanas, turismo.

\section{Abstract:}

This study analyzes the sources of information used in two projects that question the tourist model of Malaga (Spain): Urban Forest for Málaga (2016) and Torre del Puerto (2016). The first one related to the uncontrolled construction where an urban forest of 177,000 square meters is demanded and the second one with the construction of a 150-meter hotel in the city's port. The objective of the research is to analyze and compare the mentioned sources in three reference newspapers in the province and on social networks of two citizen platforms. The methodology used is mixed, qualitative and quantitative, analysis of news content and messages on social networks. The result is the existence of an obvious clash of arguments between citizens who demand a sustainable city model and press information that shows a defense of the analyzed urban projects according to institutional and private sources with private interests.

Keywords: Sources, press, social networks, citizen platforms, tourism. 


\section{Modelos de ciudad, turismo y reivindicaciones ciudadanas}

El debate en torno al modelo de ciudad así como el impacto en la convivencia y en el medioambiente de aquellas ciudades que acumulan gran afluencia de visitantes está siendo un tema recurrente en los informativos nacionales españoles. Nueva York, Boston, París, Londres, Barcelona o Madrid son ejemplos de ciudades que están viviendo un proceso de transformación permanente acusado por la llegada de miles de turistas. Esta incidencia en las ciudades de índole turística ha venido a llamarse "turistificación", que viene acompañada también de forma frecuente de la denominada gentrificación, proceso por el cual los residentes de un barrio céntrico se tienen que marchar al ser ocupado por personas de mayor poder adquisitivo. Esta práctica cuenta con antecedentes históricos, ya que la burguesía europea confinaba las viviendas sociales y las fábricas a la periferia (Le Galés, 2007). En el caso de la turistificación, la transformación está vinculada al alquiler masivo de viviendas turísticas con inquilinos de corta duración y precios elevados, aspectos que preocupan al sector y que se pone de manifiesto en el informe de Exceltur (2018), la asociación que aglutina a 28 grandes empresas del sector turístico. El problema de la turistificación radica en las situaciones de conflicto que se generan con la saturación que se produce en los centros históricos de las ciudades por un sobrepaso de la capacidad de carga, es decir, cuando los movimientos de las personas, ya sean nacionales o internacionales, exceden temporalmente el nivel aceptable por el medio ambiente, físico y humano de la zona acogida o destino (Echamendi, 2001).

El caso de Venecia ha sido uno de los más paradigmáticos, donde la repercusión de los movimientos sociales ha tenido un gran impacto. El movimiento "Comité No a las Grandes Naves" ha sido un baluarte en el rechazo del acceso a los barcos de crucero a la ciudad. En España, Palma de Mallorca y Barcelona, con 8,78 y con 8,69 millones de visitantes en 2017 según el Mastercard's Global Destination Cities Index (2018) ocupando las posiciones 16 y 17 de 162 del mundo, también es foco de movimientos de rechazo al turismo. La presión social ha logrado que el Ayuntamiento de Palma aprobase en 2018 prohibir todas las viviendas turísticas en pisos (Bohórquez, 2018), medida pionera en todo el territorio nacional. En Barcelona, los episodios de turismofobia con pancartas de desprecio al turista son frecuentes. Málaga, ciudad que acoge los dos proyectos analizados en este trabajo, ocupa actualmente el quinto lugar como destino urbano español, después de Madrid, Barcelona, Valencia y San Sebastián (Guzmán, 2017). Sin embargo, este posicionamiento en el escenario turístico hace que la ciudad también sufra los riesgos de la saturación turística como son el deterioro medioambiental, la dependencia económica basada en el turismo, las malas condiciones laborales de los trabajadores y las fricciones entre turistas y residentes, algo de lo que se hacen eco ya los medios locales y nacionales (Martín, 2018).

\section{Fuentes, medios y conflicto social}

Mientras que los ciudadanos luchan contra la gentrificación y la expulsión de las clases populares de los centros históricos y lugares claves de la ciudad, Janoschka (2018) considera que las políticas urbanas obedecen a intereses económicos. Se tejen visiones hegemónicas acerca de cómo concebir los espacios urbanos o los cambios en la ciudad en pro de un progreso que solo atiende a intereses privados. A esta visión contribuye la agenda de los medios de comunicación, que marca el interés de los ciudadanos (Luhmann, 2000). Por ello y, a pesar de marcar el modelo de ciudad, cuestiones como la demanda de un bosque urbano o la no edificación de un gran rascacielos en el Puerto de la ciudad de Málaga pasan inadvertidos para la ciudadanía frente a otras temáticas recurrentes.

Por otra parte, el periodista tiende a recurrir siempre a las mismas fuentes, aquellas que les resultan 
más fiables y accesibles. Además, "no todos los actores tienen las mismas posibilidades de hacer oír sus voces y, menos aún, de dejar plasmados sus encuadres de los acontecimientos en los medios" (Koziner, 2018, p. 103). Prieto Sánchez (2018, p. 168) observa como "el creciente número de informaciones que presentan como protagonistas a instituciones, organizaciones políticas, empresas, datos, cosas o entes, están deshumanizando la información y alejando el foco de la ciudadanía plural".

Asimismo, lo cercano también resulta más relevante y, por ello, los medios locales tienden a reflejar lo que acontece en el espacio geográfico más inmediato, otorgando más protagonismo a los políticos y sus acciones de gobierno, que a las demandas de los ciudadanos.

Por otra parte, se produce lo que Campos Freire (2008) denomina flujo activo de participación, ya que los usuarios interactúan, dialogan y pueden aportar también a través de sus comentarios, principalmente mediante herramientas como las redes sociales. Soto y Trillo (2018) consideran que no es que la televisión, la radio y la prensa hayan perdido fuerza, sino que gracias a la web y las redes sociales se encuentran más vivos que nunca en el territorio de la red.

Merece especial mención el denominado "periodismo emprendedor y ciudadano" que surge en momentos de crisis, que ejerce la profesión con financiación propia mediante la fórmula de la cooperativa. Barranquero y Sánchez (2018, p. 54) apuntan que estos medios están más comprometidos "con las demandas de ciertos sectores sociales, en especial subalternizados o poco visibles en la agenda de los medios tradicionales". Lo que podría hacernos pensar que prestan mayor atención con relación al abordaje de problemáticas sociales.

\section{Casos de análisis: Bosque Urbano para Málaga y la Torre del Puerto}

Los dos proyectos objeto de estudio de este trabajo, Bosque Urbano para Málaga y la Torre del Puerto, parten de proyectos en terrenos públicos que han levantado las reivindicaciones de colectivos sociales de la ciudad.

\section{Bosque Urbano para Málaga}

En el año 2003, el Ayuntamiento de Málaga expropió unos terrenos que habían sido de uso industrial ocupados por Repsol y cuya operación obtuvo el rechazo de la Junta de Andalucía. Sin embargo, con la aprobación en el 2011 del Plan General de Ordenación Urbana se ratificó el acuerdo. A partir de este momento, la propuesta municipal para esos terrenos ha chocado con la vecinal, que creó la plataforma Bosque Urbano Málaga. El proyecto del Consistorio pretende la construcción de cuatro rascacielos de 932 pisos, un centro comercial, oficinas, un hotel, cuatro edificios de 400 viviendas de VPO y 130.000 metros cuadrados destinados a zonas verdes.

\section{Torre del Puerto}

El denominado hotel Torre del Puerto se alzó como la propuesta ganadora de la convocatoria pública que realizó la Autoridad Portuaria para su concesión administrativa de un terreno público en el dique del puerto de la ciudad malagueña. Las características de este proyecto de 135 metros de altura (150 metros según los colectivos sociales) equivale a 35 plantas y ofrece 350 habitaciones de lujo. La dimensión de esta construcción en un lugar emblemático del puerto malagueño ha levantado las críticas de la ciudadanía, que se ha aglutinado en torno al movimiento "Defendamos nuestro horizonte". 


\section{Objetivos}

El objetivo principal de la investigación es analizar las fuentes a la que recurren los periodistas para realizar la información y las fuentes de las que obtienen información las plataformas ciudadanas, que cuestionan los modelos de ciudad y cuya información difunden a través de las redes sociales.

Entre los objetivos secundarios figuran:

- Comparar las fuentes principales y la tipología en los diarios analizados y en las redes sociales de las plataformas ciudadanas.

- Evaluar la relevancia de las fuentes en la construcción de la información en prensa y en las redes sociales.

- Determinar si se establece una proporcionalidad de las fuentes, que favorezca una información que dé voz a todas las partes implicadas.

\section{Metodología}

La metodología de este trabajo tiene un carácter mixto, utilizando el análisis de contenido desde un enfoque cualitativo y cuantitativo que nos permite identificar las fuentes e interpretar cómo construyen los relatos en los principales medios escritos y en los perfiles de las redes sociales, creados por los colectivos. Por un lado, el objeto de estudio está basado en el análisis de contenido de los tres periódicos provinciales de referencia como son Diario Sur, La Opinión de Málaga y Málaga Hoy, durante el periodo de enero 2017 a diciembre de 2018:

Tabla 1. Periódicos locales/tirada

\begin{tabular}{|l|r|}
\hline Periódicos locales & Tirada \\
\hline Diario Sur & 14.864 \\
\hline La Opinión de Málaga & 2.549 \\
\hline Málaga Hoy & 5.302 \\
\hline
\end{tabular}

Fuente: OJD (enero-2019)

La propia ficha de análisis parte de la propuesta de Fernández (2010), basada en el concepto de complementariedad, para ofrecer una amplia visión informativa desde varios puntos de vista, utilizando para ello el mayor número de fuentes consultadas así como elementos fotográficos e infográficos. Esta complementariedad se sustenta en los términos de exhaustividad (citando a Cornella, 2000) y proporcionalidad (citando a Kovac y Rosenstiel, 2003) que permiten ofrecer información veraz y precisa a los lectores. Las variables propuestas para el análisis más específico se apoyan en la clasificación propuesta por Mayoral Sánchez $(2005,95-96)$ :

\section{Información general:}

Sección:

Foto:

Gráfica:

\section{Clasificación:}

Documental

Personal 


\section{Tipos de fuente:}

Intermediario o agencia informativa

Fuentes oficiales: gobierno central, autonómico, local, sindicatos, partidos políticos, patronal, otras instituciones, etc.

Fuentes no oficiales: asociaciones, ONG, expertos, miembros de instituciones u organismos, otros.

\section{Grados de identificación de las fuentes:}

Atribución directa.

Atribución reservada.

No atribuido (fuente anónima).

\section{Tipo de información facilitada por la fuente:}

¿Es la única versión sobre un determinado hecho? Sí/No

¿Qué grado de importancia tiene esa información en el texto periodístico analizado? Mayoral Fernández (2005) establece cinco categorías que permiten evaluar esa importancia de 1 a 5 : 'anécdota', 'versión que compite con otras fuentes', 'importancia total', 'entrevista' y 'es la propia fuente la que crea un acto informativo para generar una noticia'

Por otra parte, se ha aplicado la ficha de análisis a las publicaciones y tuits aparecidos en las redes sociales de Facebook y Twitter de los colectivos "Bosque Urbano para Málaga" y "Defendamos nuestro horizonte". El periodo de análisis seleccionado es del 1 al 30 de abril de 2018 en el caso de la plataforma en defensa del "Bosque Urbano para Málaga", ya que se organiza una marcha en bicicleta al Ayuntamiento de Málaga como medida reivindicativa. El mes de noviembre de 2018, del 1 al 30 de este mes, es el periodo de análisis de las redes sociales del colectivo "Defendamos nuestro horizonte", un periodo en el que se lee un manifiesto en protesta por la posible construcción hotel rascacielos de 150 metros. Para realizar el análisis de las redes se han mantenido las mismas variables, modificando la parte de información general, a la que se ha incorporado las siguientes: post/tuit, enlaces a noticias, número de comentarios, retuits, me gusta, así como fuentes primarias y secundarias. De esta forma, se pretende determinar el alcance de interacción de la plataforma con sus seguidores así como su capacidad de actuar como fuente emisora.

\section{Tabla 2. Redes sociales analizadas}

\begin{tabular}{|l|l|l|}
\hline Colectivos sociales & Facebook & Twitter \\
\hline Bosque Urbano para Málaga & $\begin{array}{l}\text { Bosque Urbano Málaga } \\
\text { @bosqueurbanomalaga }\end{array}$ & @BosqueUrbanoMA \\
\hline Defendamos nuestro horizonte & $\begin{array}{l}\text { Defendamos Nuestro Horizonte } \\
\text { @defendamosnuestrohorizonte }\end{array}$ & @noalrascacielos \\
\hline
\end{tabular}

Fuente: Elaboración propia (2019)

\section{Resultados}

Los colectivos ciudadanos utilizan las redes sociales para comunicarse con los ciudadanos, los medios de comunicación y los actores políticos implicados. Con muchos menos seguidores que los propios medios, intentan interpelar a las administraciones y movilizar a la ciudadanía a través de Facebook y Twitter. La plataforma "Bosque Urbano para Málaga" cuenta con un mayor número de seguidores en Facebook, 
SILVIA OLMEDO SALAR y PALOMA LÓPEZ VILLAFRANCA: Análisis de un modelo de ciudad turística según las fuentes del relato: prensa versus plataformas ciudadanas. ¿Especulación o desarrollo?

unos 5.000 más que en Twitter, aunque la actividad es prácticamente la misma en ambas redes sociales. "Defendamos nuestro horizonte" tiene mayor actividad y mayor número de seguidores en Twitter, más del doble (1.776 en Twitter frente a 720 en Facebook).

Tabla 3. Seguidores de las plataformas de los colectivos sociales

\begin{tabular}{|l|l|l|}
\hline Colectivos sociales & Facebook & Twitter \\
\hline Bosque Urbano para Málaga & 7.291 seguidores & 2.112 seguidores \\
\hline Defendamos nuestro horizonte" & 720 seguidores & 1.776 seguidores \\
\hline
\end{tabular}

Fuente: Twitter y Facebook. Elaboración propia (2019)

Durante el periodo analizado, la plataforma "Bosque Urbano para Málaga" realiza prácticamente la misma actividad en Facebook y Twitter, mientras que "Defendamos nuestro horizonte" es más activa en Twitter que en Facebook, publica casi el doble en esta red social.

Tabla 4. Post y tuits de las plataformas BUM y Rascacielos (Torre del Puerto)

\begin{tabular}{|l|l|l|}
\hline Redes sociales & BUM & Rascacielos (Torre del Puerto) \\
\hline Facebook (posts) & 16 & 8 \\
\hline Twitter (tuits) & 16 & 33 \\
\hline
\end{tabular}

Fuente: Elaboración propia (2019). Periodo de análisis del 1 al 30 de abril de 2018 (Bosque Urbano) y del 1 al 30 de noviembre de 2018 (Rascacielos)

La plataforma en defensa del "Bosque Urbano para Málaga", BUM, tiene un mayor número de post y tuits propios frente a las noticias que los propios colectivos comparten de los medios de comunicación. Durante el periodo analizado, un 30\% de posts están relacionados con noticias de medios de comunicación en Facebook y en Twitter, un 44\% de noticias de otros medios. El colectivo "Defendamos nuestro horizonte" no comparte durante el periodo analizado ninguna noticia de medios de comunicación en Facebook y en Twitter solo un 15\% de los tuits están relacionados con noticias de medios de comunicación. El resto es información o mensajes de elaboración propia.

Con respecto a los comentarios y "me gusta" en redes sociales de ambas plataformas en el periodo analizado, en el que ambos colectivos organizan actos de movilización, señalamos que "Bosque Urbano para Málaga" cuenta con 51 comentarios y 1.581 likes en Facebook, 4 comentarios en Twitter, 400 retuits y 517 likes. $Y$ "Defendamos nuestro horizonte" 16 comentarios, 25 compartidos y 45 me gusta en Facebook y en Twitter tienen 40 comentarios, 439 retuits y 496 likes. Por lo tanto, el impacto de Bosque Urbano es mayor en Facebook, pese a tener más seguidores en Twitter y "Defendamos nuestro horizonte" es más activo en Twitter, donde cuenta con más del doble de seguidores.

En ocasiones, interpelan a los políticos relacionados con sus reivindicaciones y la plataforma "Defendamos nuestro horizonte" se refiere específicamente a las partes implicadas, con objeto de obtener respuesta de los usuarios mencionados en Twitter. Hay que señalar que obtienen respuesta de quienes están cerca de sus intereses frente a la parte contraria. Así, como se aprecia en el siguiente ejemplo, IU, Unidos Podemos y Málaga Ahora contestan a sus preguntas o interpelaciones a través de las redes frente 
a la inexistente respuesta de los partidos PP o PSOE, con postura contraria ante la polémica construcción del rascacielos del puerto malagueño.

Imagen 1. Captura de los tuits de la plataforma "Defendamos Nuestro Horizonte" interpelando a los políticos municipales

No al Rascacielos @noalrascacielos.25 nov. 2018

.@JuanMa_Moreno ¿Cual es la posición de la candidatura de @PPMalaga \#EleccionesAndaluzas, ante la pretendida construcción de un \#Rascacielc Morro de Levante de nuestro Puerto de Málaga?.

\#DefendamosNuestroHorizonte

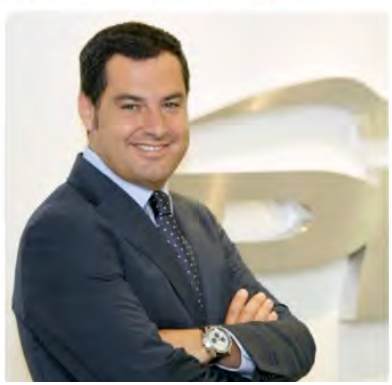

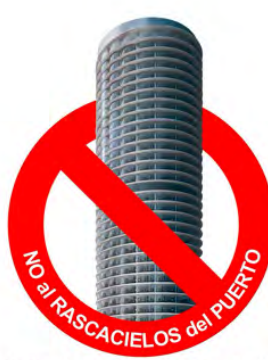

Defendamos Nuestro Horizont

\section{No al Rascacielos @noalrascacielos · 25 nov. 2018}

.@ruiz_espejo ¿Cual es la posición de la candidatura de @psoedeandaluci las \#EleccionesAndaluzas, ante la pretendida construcción de un \#Rascac en el Morro de Levante de nuestro Puerto de Málaga?.

\#DefendamosNuestroHorizonte

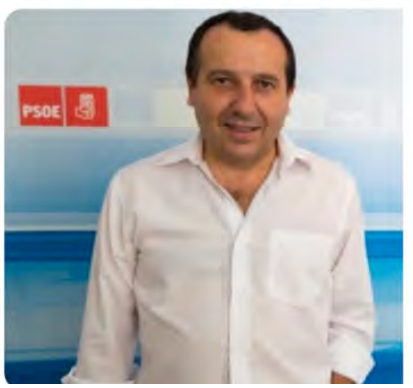

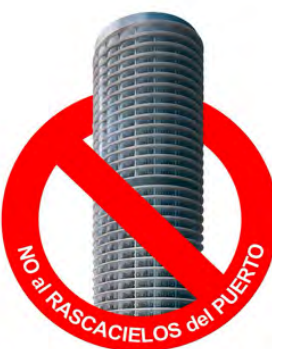

Defendamos Nuestro Horizont

No al Rascacielos @noalrascacielos · 25 nov. 2018

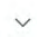

@ @eresaRodr_¿Cual es la posición de la candidatura de @AdelanteAND, a las \#EleccionesAndaluzas, ante la pretendida construcción de un \#Rascacielos en el Morro de Levante de nuestro Puerto de Málaga?.

\#DefendamosNuestroHorizonte
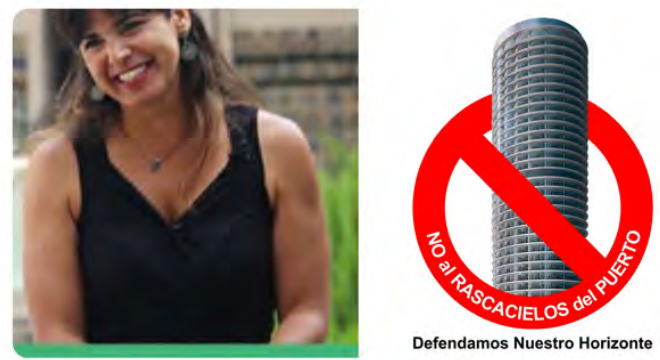

Fuente: Twitter "Defendamos nuestro horizonte" 
Las fuentes que generan dicha información o a las que recurren para lanzar sus mensajes son fundamentalmente primarias, porque suelen ser ellos quienes además generan esta información con atribución directa de la autoría. "Bosque Urbano para Málaga" genera información procedente de fuentes primarias en un $80 \%$ de los posts analizados en Facebook y $60 \%$ de fuentes primarias en los tuis. La plataforma "Defendamos nuestro horizonte" recurre a fuentes primarias en el $100 \%$ de los posts de Facebook y $87 \%$ de fuentes primarias en Twitter. Por lo tanto, si ellos generan información sus mensajes no proceden de fuentes oficiales, si consideramos como tales al Ayuntamiento, partidos políticos de la oposición y otros organismos acreditados como tales.

Tabla 5. Tipos de fuentes informativas en redes sociales: caso BUM/Torre del Puerto

\begin{tabular}{|l|l|l|l|l|}
\hline & \multicolumn{2}{|l|}{ BUM } & \multicolumn{2}{l|}{ Torre del Puerto } \\
\hline Redes Sociales & Oficiales & No Oficiales & Oficiales & No Oficiales \\
\hline Facebook & 1 & 15 & 0 & 8 \\
\hline Twitter & 3 & 13 & 4 & 29 \\
\hline Total & $\mathbf{4}$ & $\mathbf{2 8}$ & $\mathbf{4}$ & $\mathbf{3 7}$ \\
\hline
\end{tabular}

Fuente: Elaboración propia (2019)

Las fuentes son personales en el 73\% de los posts de Facebook del Bosque Urbano, el resto proceden de agencias o de otras fuentes y en Twitter, sin embargo, proceden de otras fuentes como agencias o de otro origen documental en el $53 \%$ de los tuits analizados. El colectivo "Defendamos nuestro horizonte" recurre en Facebook siempre a fuentes primarias y en Twitter en un $71 \%$ de los tuits que son objeto de estudio. La atribución directa a las fuentes es muy evidente en las redes sociales, en el $81 \%$ de los posts y tuits analizados del Bosque Urbano hay una atribución a una fuente determinada. En el caso de la plataforma contraria al rascacielos, el $100 \%$ de los posts de Facebook tienen una atribución directa y ocurre lo mismo en el $84 \%$ de los tuits analizados.

Tabla 6. Grado de identificación de las fuentes: BUM/Torre del Puerto

\begin{tabular}{|l|l|l|l|l|l|l|}
\hline & \multicolumn{2}{|l|}{ BUM } & \multicolumn{2}{l|}{ Torre del Puerto } \\
\hline $\begin{array}{l}\text { Redes } \\
\text { Sociales }\end{array}$ & $\begin{array}{l}\text { Atribución } \\
\text { directa }\end{array}$ & $\begin{array}{l}\text { Atribución } \\
\text { reservada }\end{array}$ & No atribuido & $\begin{array}{l}\text { Atribución } \\
\text { directa }\end{array}$ & $\begin{array}{l}\text { Atribución } \\
\text { reservada }\end{array}$ & No atribuido \\
\hline Facebook & 13 & 1 & 2 & 8 & 0 & 0 \\
\hline Twitter & 13 & 0 & 3 & 28 & 1 & 5 \\
\hline Total & $\mathbf{2 6}$ & 1 & 5 & 36 & 1 & 5 \\
\hline
\end{tabular}

Fuente: Elaboración propia (2019)

Comprobamos en los tuits y posts que se comparte una única versión de la noticia en el $75 \%$ de los casos analizados en Facebook y el $81 \%$ en Twitter del Bosque Urbano de Málaga. En el caso de la plataforma contra la construcción del rascacielo, el 100\% de las noticias es única versión en Facebook y el $90 \%$ en Twitter. 
Las informaciones que comparten estos colectivos en las redes afectan al Bosque Urbano de Málaga en el $94 \%$ de los casos en Facebook y el $100 \%$ en Twitter. Y en el caso de la plataforma en defensa de un puerto sin rascacielos afecta al 100\% en ambas redes sociales. El grado de importancia de los textos para los colectivos es el máximo, puesto que son ellos mismos quienes comparten en redes y, por tanto, son ellos quienes generan estos mensajes. El Bosque Urbano de Málaga, BUM, genera el $88 \%$ de las informaciones en Facebook y el 75\% en Twitter. La plataforma "Defendamos nuestro horizonte" genera como fuente informativa el 100\% de las informaciones en Facebook y el $85 \%$ en Twitter.

La imagen es importante para estas plataformas, que siempre suelen utilizar su simbología a través del bosque o el rascacielos para llamar la atención de los usuarios/ciudadanos. "Bosque Urbano para Málaga" utiliza el grafismo o ilustración del bosque en el $50 \%$ de sus posts en Facebook, frente al $40 \%$ de fotografías y un $10 \%$ de posts sin imágenes. En Twitter sin embargo recurren más a las fotografías, $50 \%$ frente al $31 \%$ de ilustraciones y el resto de tuits no se acompañan ni por imágenes ni por ilustraciones. "Defendamos nuestro horizonte" utiliza siempre fotografías en sus posts en Facebook, mientras que en Twitter utilizan imágenes en el $84 \%$ de los casos, ilustraciones o gráficos en el $6 \%$ de los casos y el resto de tuits no van acompañados de imágenes.

Imagen 2. Ilustración del Proyecto del Bosque Urbano de Málaga

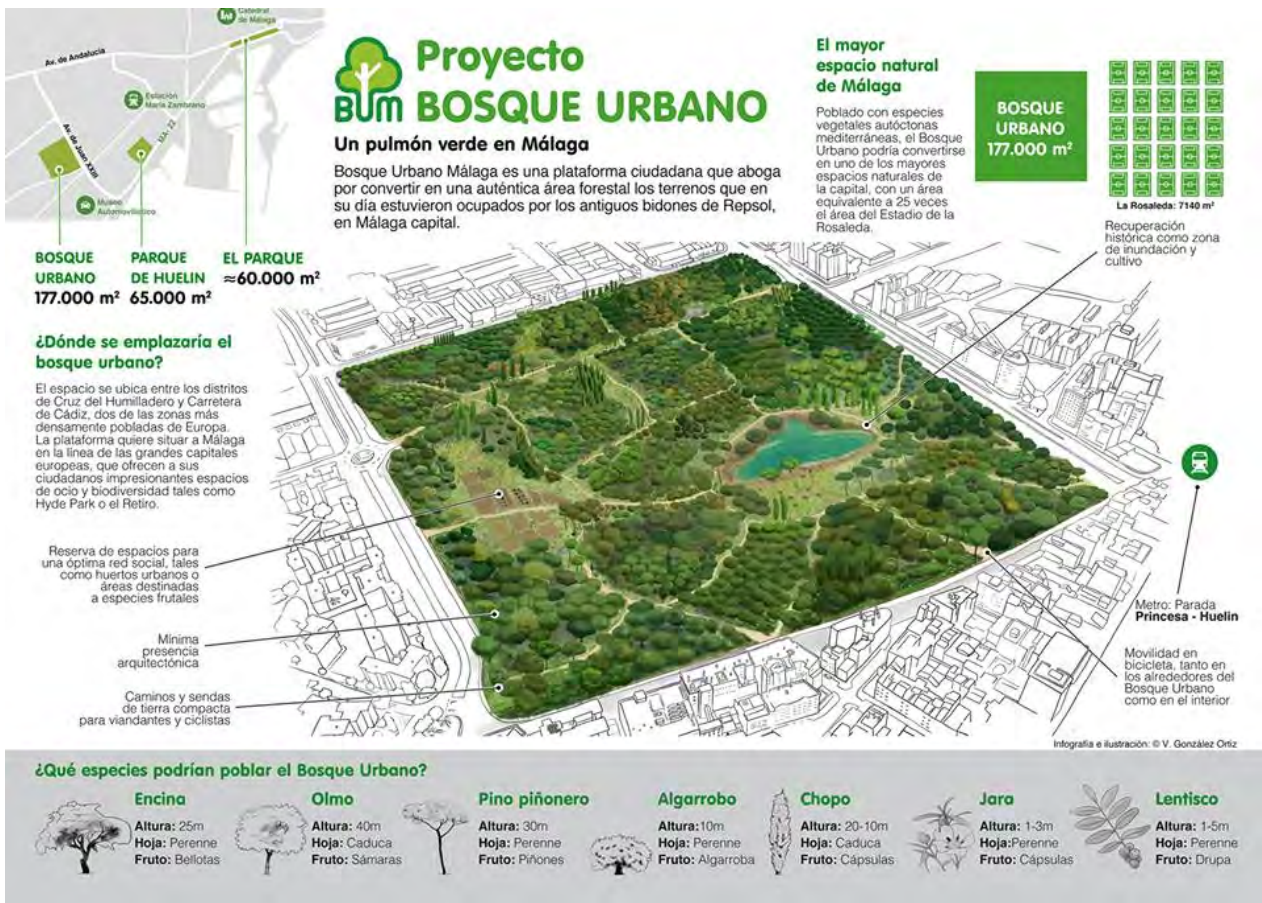

Fuente: Plataforma Bosque Urbano de Málaga 
Imagen 2. Fotomontaje de la posible ubicación del rascacielos en el Puerto de Málaga

\section{No al Rascacielos @noalrascacielos·25 nov. 2018}

Un proceso electoral es el momento para que las distintas candidaturas que optan al Gobierno y al Parlamento Andaluz, manifiesten su posición respecto a aquellas cuestiones, como la planteada por nuestro colectivo, que son de la preocupación de la ciudadanía. \#NoAIRascacielos
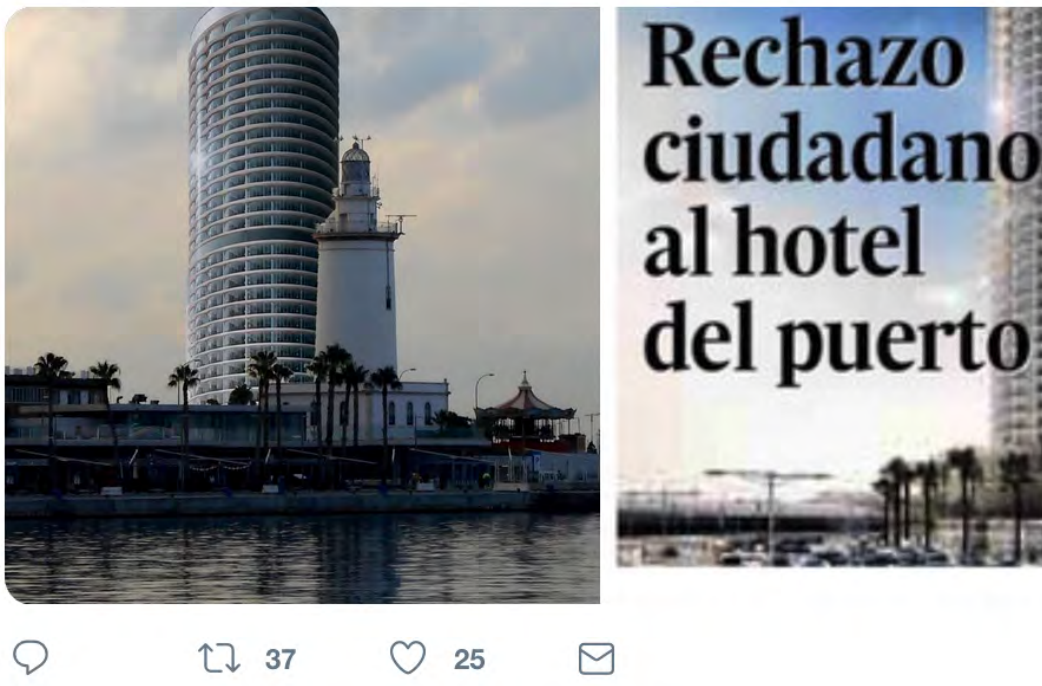
al hotel del puerto

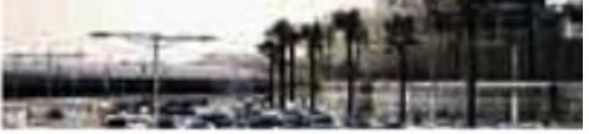

Fuente: Twitter "Defendamos nuestro horizonte"

En el caso de la prensa, el Diario Sur cubre de manera más continuada la información de ambos proyectos, aunque en todos los periódicos se evidencia un mayor interés informativo por la Torre del Puerto a lo largo del tiempo analizado. Este aspecto se contempla en la aparición de 57 noticias sobre la Torre del Puerto en Diario Sur frente a las 19 aparecidas en el mismo periodo relacionadas con el BUM. Esta mayor cobertura informativa se replica en los otros medios, donde en Málaga Hoy alcanza las 25 noticias a diferencia de las 3 sobre el Bosque Urbano mientras que La Opinión publica 17, duplicando las 8 dedicadas al BUM.

Tabla 7. Noticias en la prensa sobre BUM/Rascacielos

\begin{tabular}{|l|l|l|}
\hline Periódicos & BUM & Rascacielos (Torre del Puerto) \\
\hline Diario Sur & 19 & 57 \\
\hline La Opinión de Málaga & 8 & 17 \\
\hline Málaga Hoy & 3 & 25 \\
\hline
\end{tabular}

Fuente: Elaboración propia (2019) 
Las fuentes utilizadas ponen sobre la mesa el dominio de las personales sobre las documentales, haciendo uso de un periodismo declarativo, que atiende a los actores, especialmente, los políticos locales. En el caso de BUM, el 100\% de las fuentes que figuran en las informaciones del Diario Sur (24) y del Málaga Hoy (3) son personales, mientras que La Opinión de Málaga hace en un 22,2\% uso de las documentales (2) mientras que el $88 \%$ (7) son personales. Estos datos dejan ver la consolidación de las fuentes personales como las principales surtidoras de información.

Gráfico 1. Fuentes personales y documentales en la prensa (BUM)

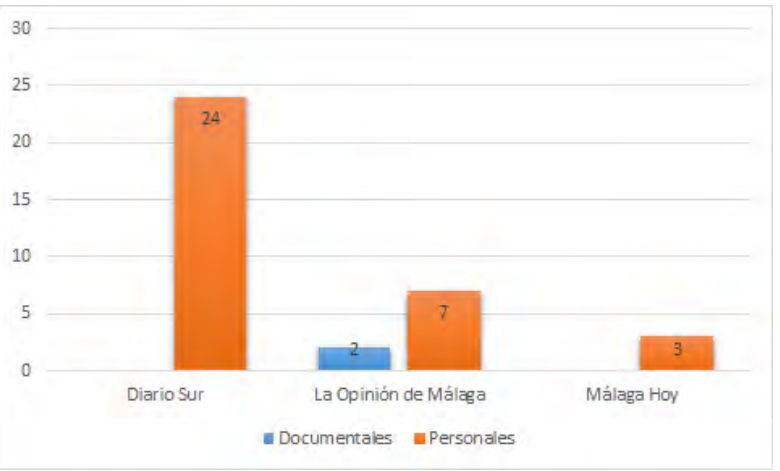

Fuente: Elaboración propia (2019)

En el tema de la Torre del Puerto se detecta una mayor recurrencia a fuentes documentales, que estaría motivado por la relevancia de los informes técnicos y medioambientales que son de interés para el devenir del proyecto. Además, los periódicos recurren también a notas remitidas por las partes implicadas. Frente a los datos del análisis de BUM, en las informaciones sobre el rascacielos todos los periódicos van a hacer uso de las fuentes documentales, destacando Diario Sur con 13 apariciones, seguido del Málaga Hoy con 7 y La Opinión con 1, que también la combina en una información con fuente personal, por lo que sumaría dos ocasiones. Las fuentes personales siguen siendo la principal vía de información: 69 apariciones en Diario Sur y 15 tanto en La Opinión como en Málaga Hoy. Si enfrentamos el número de fuentes con las noticias publicadas, se observa que prácticamente son una fuente por noticia, a excepción de algunas que logran una mayor polifonía de voces, oscilando entre las 2 y las 4 fuentes, por lo que se pone de manifiesto que no es la práctica habitual, pero sí debería ser la deseable para lograr una mayor proporcionalidad en los enfoques de la información. 
Gráfico 2. Fuentes personales y documentales en la prensa (Rascacielos)

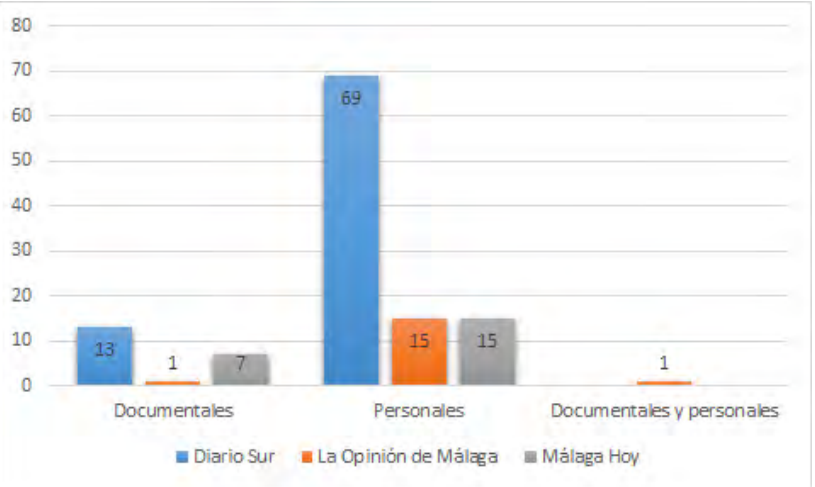

Fuente: Elaboración propia (2019)

Sobre la tipología de fuentes se sigue la tónica predominante del dominio de las fuentes oficiales, que están ligadas especialmente a los representantes del gobierno municipal y de la oposición. Sin embargo, se detecta una representatividad significativa de las fuentes no oficiales en la figura de los colectivos sociales que lideran las reivindicaciones de los dos proyectos. Este hecho se produce especialmente en el caso de BUM, donde la acción informativa del movimiento social parte principalmente de la Plataforma del Bosque Urbano para Málaga. A diferencia de ello, en la Torre del Puerto muchos organismos y representantes públicos están presentes en los acontecimientos que se desarrollan o son los motivadores de los mismos. En BUM, el 56\% (26) son fuentes oficiales frente al $44 \%$ (19) de las no oficiales, siendo el Diario Sur con un mayor número de noticias, el que tiene más fuentes oficiales (18), seguido de La Opinión (4) y Málaga Hoy (2). Curiosamente, en La Opinión las fuentes no oficiales superan de forma significativa a las oficiales ( $71 \%$ frente al $29 \%$ ), es decir, que las narrativas de los colectivos y agentes sociales han tenido una mayor presencia que las oficiadas por los representantes públicos.

En la Torre del Puerto, el mayor peso lo adquieren las fuentes oficiales con un $66 \%$ mientras que las no oficiales representan el 44\%, siendo el Diario Sur y Málaga Hoy los que hacen un uso más relevante de esta tipología con la aparición de 52 fuentes oficiales frente a las 27 no oficiales y 21 oficiales frente a 8 no oficiales, respectivamente. De nuevo, La Opinión evidencia un mayor equilibrio en ambas tipologías con 12 oficiales y 8 no oficiales.

Tabla 8. Tipos de fuentes informativas: caso BUM/ Rascacielos (Torre del Puerto)

\begin{tabular}{|l|l|l|l|l|}
\hline & \multicolumn{2}{|l|}{ BUM } & \multicolumn{2}{l|}{ Rascacielos (Torre del Puerto) } \\
\hline Periódicos & Oficiales & No Oficiales & Oficiales & No Oficiales \\
\hline Diario Sur & 18 & 8 & 52 & 27 \\
\hline La Opinión de Málaga & 4 & 10 & 12 & 8 \\
\hline Málaga Hoy & 2 & 1 & 21 & 8 \\
\hline Total & $\mathbf{2 4}$ & $\mathbf{1 9}$ & $\mathbf{8 5}$ & $\mathbf{4 3}$ \\
\hline
\end{tabular}

Fuente: Elaboración propia (2019) 
Hay que decir que se ha incorporado una variable denominada "acto", ya que existen informaciones que relatan acontecimientos, pero sin fuentes que lo transmitan. Pero se deduce por la presencia del periodista en el hecho o su conocimiento, aunque sin mencionar cuál es la fuente (por ejemplo, reuniones entre el alcalde y el promotor del hotel). En este sentido, se han registrado 2 actos de esta tipología en las informaciones del Bosque Urbano y 4 en la Torre del Puerto, todas ellas en el Diario Sur.

La atribución directa es la fórmula más empleada en todas las informaciones y en todos los periódicos analizados, permitiendo una identificación clara y concisa de la fuente de información: $84 \%$ son de atribución directa tanto en BUM como en la Torre del Puerto. Sin embargo, es preciso mencionar la existencia de informaciones cuyas fuentes no quedan reflejadas, circunstancia que se produce en 9 ocasiones, sumando las noticias de ambos proyectos, y que nos lleva a hacer hincapié en la necesidad de evitar esta falta de información a los lectores. Por otra parte, destaca la escasa presencia de atribuciones reservadas, más vinculadas a otro tipo de noticias.

Tabla 10. Grado de identificación de las fuentes: BUM/Torre del Puerto

\begin{tabular}{|c|c|c|c|c|c|c|}
\hline \multirow[b]{2}{*}{ Periódicos } & \multicolumn{3}{|l|}{ BUM } & \multicolumn{3}{|c|}{ Torre del Puerto } \\
\hline & $\begin{array}{l}\text { Atribución } \\
\text { directa }\end{array}$ & $\begin{array}{l}\text { Atribución } \\
\text { reservada }\end{array}$ & No atribuido & $\begin{array}{l}\text { Atribución } \\
\text { directa }\end{array}$ & $\begin{array}{l}\text { Atribución } \\
\text { reservada }\end{array}$ & No atribuido \\
\hline Diario Sur & 22 & 2 & 2 & 72 & 4 & 1 \\
\hline $\begin{array}{l}\text { La Opinión de } \\
\text { Málaga }\end{array}$ & 14 & 0 & 1 & 17 & 0 & 0 \\
\hline Málaga Hoy & 1 & 0 & 2 & 20 & 2 & 3 \\
\hline Total & 37 & 2 & 5 & 109 & 6 & 4 \\
\hline
\end{tabular}

Fuente: Elaboración propia (2019)

En lo que respecta al caso del Bosque Urbano, el Diario Sur sólo aporta en 4 ocasiones más de una versión sobre el acontecimiento, 3 la Opinión y 3 Málaga Hoy. En la Torre del Puerto, Diario Sur contempla en 12 ocasiones una mayor variedad a las versiones de los acontecimientos, La Opinión un total de 9 y Málaga Hoy que registra 10 noticias con más de una versión frente a 15 que relata una única perspectiva. Respecto al grado de importancia que tiene la información aportada por las fuentes en los textos periodísticos analizados, de forma generalizado el nivel 5 (es la propia fuente la que crea un acto informativo para generar una noticia) es el más recurrente. Se produce una dinámica repetitiva de creación de información por parte de los colectivos y de los representantes políticos para estar en la agenda mediática, por lo que la proactividad en este sentido es un elemento presente en ambas partes. En BUM, todas las informaciones publicadas parten de las propias fuentes protagonistas de la noticia, excepto en un caso recogido por Sur, que es un incendio en los terrenos del Bosque Urbano.

Encontramos una mayor variedad de niveles en las noticias sobre la Torre del Puerto, ya que se producen otros escenarios como entrevistas al representante de la promotora, al alcalde o los plenos municipales, en los que los representantes vierten sus opiniones. Por ello, el nivel 5, líder en Sur (34 noticias), La Opinión (16) y Málaga Hoy (23) va a estar acompañado del nivel 4 (entrevista) en 4 ocasiones en el Diario Sur, en 1 en La Opinión y de dos en Málaga Hoy. El nivel 3 (importancia total) únicamente se localiza en 
Sur en 12 ocasiones, y vendría determinado por la presencia de noticias que informan sobre el proceso administrativo de los informes técnicos.

El grado de importancia de estas informaciones para el colectivo en redes es de nivel 5 prácticamente en todos los mensajes y noticias que difunden. No existe una proporción en cuanto a las fuentes implicadas en las temáticas porque incluso cuando intentan obtener respuesta en redes sociales de las administraciones no obtienen feedback a los tuits o posts. Además, las redes sociales se convierten en la herramienta que los colectivos ciudadanos utilizan para manifestarse y hacer llegar a los ciudadanos y medios de comunicación sus propias inquietudes.

Las informaciones vienen acompañadas por fotografías de forma regular: todas las informaciones vertidas sobre el Bosque Urbano, excepto en dos ocasiones, son complementadas con una fotografía mientras que en el caso de la Torre del Puerto de las 99 noticias, solo 9 no se acompañan con fotografías. Ello demuestra la importancia otorgada a la información. No obstante, en el caso de BUM las imágenes tienen que ver con las acciones emprendidas por los colectivos (manifestaciones, siembra de árboles, etc.) mientras que en la Torre del Puerto se recurre de forma repetitiva a fotografías de las maquetas de la construcción.

\section{Discusión}

El análisis expuesto muestra cómo los colectivos ciudadanos actúan como fuentes emisoras a través de las redes sociales, por tanto son fuentes primarias, identificadas, con atribución directa. Las plataformas no recurren a fuentes oficiales como tal, sino que se convierten en emisores. En el caso de utilizar fuentes oficiales es para rebatir sus argumentos o replicar sus actuaciones, apelando incluso a las administraciones a través de los políticos para que se posicionen. Sus voces vienen a irrumpir en un escenario, cuyo valor de la noticia estaba cimentado en la proximidad geográfica, la relevancia social de la fuente y la fractura del consenso social (news value) (Pérez, Gutiérrez, Sánchez y Zurbano, 2015). Pero ahora esa voz relevante, es la voz de los representantes sociales.

En las redes lanzan mensajes que pretenden persuadir a la ciudadanía. En ocasiones, los difunden apoyados por noticias de la prensa, que favorezcan sus posturas o contrarias para rebatirlas. Las fuentes se implican muy directamente en los mensajes de las plataformas, mayoritariamente con versiones únicas, y en una proporción minoritaria con el apoyo de fuentes complementarias. Esto se debe a que las fuentes de estas informaciones suelen ser los propios miembros de la plataforma y cuando aparecen fuentes complementarias son manifestaciones de los políticos sobre el conflicto y la correspondiente respuesta del colectivo.

Las noticias en los periódicos locales siguen manteniendo un patrón conservador en la construcción informativa, donde abundan las fuentes oficiales, lideradas por los representantes políticos locales como se sigue constatando en la literatura académica (Rodríguez, Enguix, Rojas, García, 2015). No obstante, se vislumbra un proceso de posicionamiento de las voces de la ciudadanía, que utilizan los cauces de la movilización social, los actos simbólicos como la plantación de árboles, y los actos públicos de los representantes locales para visibilizar sus demandas. El manejo de las estrategias de comunicación a través de notas, contacto con los periodistas o la conversión en una fuente autorizada favorece la aparición de los discursos de la ciudadanía movilizada. 


\section{Conclusiones}

El conjunto de las noticias publicadas enfrenta dos relatos y dos grandes tipos de fuentes, aquellas interesadas en una dimensión turística, económica y social (Ayuntamiento, empresarios, promotores) y otras (Plataformas, Ecologistas en Acción, ONG, etc.) que esgrimen principios de respeto al espacio público, al medio ambiente y que apuestan por un modelo de ciudad sostenible y más dirigido a los residentes que a los turistas. Aunque la proporcionalidad de las fuentes no está totalmente lograda en las noticias de los periódicos, el relato de los colectivos se deja escuchar en el escenario mediático, que ven fortalecido su mensaje a través de las redes sociales donde se dirige a un público entregado y/o interesado a la causa que, a su vez, replica la narrativa. Este hecho, hace que el discurso de los movimientos sociales logre un mayor eco, que se suma a la resonancia lograda como fuente en los medios tradicionales.

La prensa recoge las versiones oficiales que muestran las bondades de los proyectos urbanísticos y ligan el progreso a la inversión de los promotores, según apreciamos en la alocución de las fuentes que tienen predominio en prensa (alcalde, portavoces de administraciones, empresas implicadas).

Las plataformas ciudadanas no aparecen representadas en prensa con la fuerza y el argumentario que tienen en redes y no hay ningún tipo feedback con quienes defienden una política de urbanismo especulativo, por lo que no existe igualdad de condiciones por falta de visibilidad y representación en los medios analizados.

\section{Referencias bibliográficas}

- Barranquero Carretero, A. y Sánchez Moncada, M. (2018). Cooperativas de medios en España. Un periodismo emprendedor y ciudadano en tiempos de crisis. REVESCO: Revista de estudios cooperativos, (128), pp. 36-58.

- Bohórquez, L. (2018). Palma será la primera ciudad en prohibir todas las viviendas turísticas en pisos. El País (24/04/2018). Disponible en: https://elpais.com/economia/2018/04/23/actualidad/1524493873 547313.html

- Campos Freire, F. (2008). Las redes sociales trastocan los modelos de los medios de comunicación tradicionales. Revista Latina de Comunicación Social, 63, pp. 287- 293.

- Echemendi, L. (2001). La capacidad de carga turística. Aspectos conceptuales y normas. Anales de Geografía, 21, pp. 11-30.

- Excelsur (2018). Informe Perspectiva Turística. Balance Turismo Empresarial del Primer Trimestre de 2017. (60), abril. Disponible en: https://www.exceltur.org/wp-content/uploads/2017/04/ Informe-Perspectivas-Tur\%C3\%ADsticas-N\%C2\%BA60-IT-2017-y-perspectivas-para-IIT-y-Semana-Santa-2017.pdf

- Fernández Gil, J. R. (2010). Fuente de análisis para el estudio de la prensa diaria. Anales de Documentación, (13), pp. 135-158.

- Guzmán, V. (2017, 24 de mayo). Málaga es el quinto destino más competitivo de España. La Opinión de Málaga. Disponible en: https://www.laopiniondemalaga.es/turismo/2017/05/24/malaga-destino-turistico-competitivo/932786.html

- Janoschka, M. (2018). Gentrificación en España reloaded. Papers: Regió Metropolitana de Barcelona: Territori, estratègies, planejament, (60), pp. 24-33.

- Koziner, N. (2018). Standing de las fuentes periodísticas en la política de medios argentina (2009 y 2016). Cuadernos, info, (42), pp. 101-118.

- $\quad$ Le Galés, P. (2007). Las Ciudades Europeas. Conflictos Sociales y Gobernanza. Madrid: Comunidad de Madrid. 
- Luhmann, N. (2000). La Realidad de los Medios de Masas. Anthropos. Barcelona: Universidad Iberoamericana, Iteso.

- Martín Muñoz, A. (2018). Reflejo del Impacto negativo de la actividad turística en los medios de comunicación de Málaga. [Trabajo Fin de Grado]. Universidad de Málaga: Málaga, España. Disponible en: https://riuma.uma.es/xmlui/bitstream/handle/10630/16923/Mart\%C3\%ADn\%20Mu\%C3\%B10z,\%20Aida.pdf?sequence $=1$

- Monti, J. (2018). Mastercard. Global Destination Cities Index [en línea]. [Fecha de consulta: 2 de mayo de 2019]. Disponible en: https://newsroom.mastercard.com/press-releases/big-cities-big-businessbangkok-london-and-paris-lead-the-way-in-mastercards-2018-global-destination-cities-index/

- Mayoral Sánchez, J. (2005) Fuentes de información y credibilidad periodística. Estudio sobre el Mensaje Periodístico, 11, pp. 93-102.

- $\quad$ Pérez, C.; Gutiérrez, D.; Sánchez, T.; y Zurbano, B.(2015). El uso de fuentes periodísticas en las secciones de Política, Economía y Cultura en el Periodismo de Proximidad Español. Estudios sobre el Mensaje Periodístico. Especial noviembre "Periodismo e información de calidad", pp. 101-117.

- Prieto Sánchez, C. (2018). ¿Quiénes hablan en las noticias? Desequilibrio de género en las fuentes informativas de la prensa de proximidad. ZER: Revista de Estudios de Comunicación= Komunikazio Ikasketen Aldizkaria, 23(45).

- Rodríguez, A.; Enguix A.; Rojas, J. L.; y García . M. (2015). La calidad de los medios y el uso de fuentes periodísticas en la prensa local de referencia en España. Estudios sobre el Mensaje Periodístico. Especial noviembre "Periodismo e información de calidad", pp.85-100.

- $\quad$ Trillo Pacheco, J.J. y Soto Molina, J. (2018). El poder de los medios masivos tradicionales y las plataformas digitales en el activismo político. Encuentros, 16 (2), pp. 62-78.

\section{CURRICULUM VITAE}

SILVIA OLMEDO SALAR

Silvia Olmedo Salar es doctora en Periodismo y profesora del Departamento de Periodismo de la Universidad de Málaga. Su línea de investigación se centra en el estudio de indicadores de rentabilidad social en comunicación; cooperación, comunicación y desarrollo, y nuevas narrativas sonoras. Docente invitada en cursos de posgrado y seminarios de formación, ha colaborado activamente en proyectos competitivos de investigación y de innovación educativa. Ha realizado estancias de investigación en la Universidad de Stirling (Escocia), de Roskilde (Dinamarca) y de Sheffield (Reino Unido). Los resultados de su trabajo se han difundidos en libros y en revistas nacionales e internacionales y es revisora de revistas como Journal of Applied Journalism \& Media Studies. Como profesional, ha trabajado como periodista en medios escritos, radio y agencias de noticias.

\section{PALOMA LÓPEZ VILLAFRANCA}

Paloma López Villafranca es doctora por la Universidad de Málaga y profesora en esta Universidad desde 2009, en el Departamento de Comunicación Audiovisual y Publicidad. Especialista en narrativa sonora, podcasting, radio, comunicación organizacional, ha publicado libros, capítulos de libros y artículos sobre esta temática. Ha realizado estancias de investigación en la Universidad de Sheffield (Inglaterra), la Universidad de Minho (Portugal) y la Universidad de Sapienza (Italia). Y ha desarrollado su labor profesional como periodista para el Grupo Prisa, Recoletos, entidades municipales, además de colaborar en el año 1998 en Rne. 